\title{
Women Linguistic Features in the Craig Gillespie's Movie “I, Tonya”
}

\author{
I Kadek Purnata $^{1}$, Made Budiarsa ${ }^{2}$, Ni Ketut Sri Rahayuni ${ }^{3}$ \\ Udayana University, Denpasar, Bali, Indonesia \\ Correspondence e-mail: kadekpurnatha@gmail.com, made_budiarsa@yahoo.com, \\ sri_rahayuni@unud.ac.id
}

\begin{abstract}
Lakoff's assertion about women's language was a breakthrough in linguistics. However, many linguists and researchers also criticized and stated different perspectives towards Lakoff's theory. Therefore, this study was conducted to know whether Lakoff's theory is still relevant nowadays. This study used the movie "I' Tonya" as the data source. It was applied with quantitative and qualitative analysis. It is a documentation method supported with a corpus analysis based on the concordance technique using AntConc software. The findings show that nine types of women's linguistics features were used by the female characters in the "I' Tonya" movie. Meanwhile, one type of women linguistics feature of the precise color term was not found. From 10677 words of corpus data from "I' Tonya" subtitles script, women used lexical hedges accounting for $64 \%$ while men only $36 \%$. It was also found in intensifier where women used accounting for 103 expressions and men only 37 expressions. However, in avoidance of strong swear words, women were using swear words about $71 \%$ compared to only $28 \%$ used by men.
\end{abstract}

Keywords: women's linguistic features, women linguistics functions, quantification.

\section{INTRODUCTION}

Women's language does not develop in certain areas or owned by a particular society. It is only naturally owned by females. The term women's language became popular and developed in the early 1970s by a linguist named Robin Lakoff. She stated facts about the characteristics of women's language, such as; in speaking style, the way women express their intention through words is considered to be indirect, weak, and polite (Lakoff, 2004). Moreover, this language style also affected their job. Women usually occupy lower positions such as secretary, bank teller, and waitress, while men occupy higher positions such as supervisors and managers. (Crawford, 1995)

Lakoff's theory does not prove that women only use all the features of women's language, but men also use them. The fundamental thing about this difference is only the quantity of the usage of these linguistic features. Women use it more and predominantly than men.

Many linguists and researchers also criticized and stated different perspectives towards Lakoff's theory. Hall and Bucholtz note that Lakoff's claims lack empirical evidence. Most of her findings were by scholars in the empirically oriented social sciences (anthropology, psychology, sociology, speech communication) (1995, p. 3). Similarly, Holmes points out that Lakoff's assertions were based on her intuitions and observations, and much of her initial research was methodologically unsatisfactory (2008, p. 303). O'Barr and Atkins argued that Lakoff's description of women's linguistic features is inaccurate. They show that the frequency of women's language features in the speech correlates not with gender but with two other factors: first, with the speaker's social status; and the speaker's experience (2015, p. 109).

Nowadays, men's and women's existence are equal. The term "subordinate" has vanished. Women and men can interact without depending on gender status. We can observe their activity that most people of different gender already interact with each other. In association with different genders, it will also cause a language change. As expected, the number of linguistic features belonging to women will differ from its fundamentals.

Therefore, to know whether Lakoff's theory is still relevant nowadays, the study of women's language was interesting to be conducted in a movie, especially a movie of: "I, Tonya."

\section{Method And Theory}

\section{A. Research Method}

The mixed-method was applied in this study. It is a combination of qualitative and quantitative methods. The limitation and strengths possessed by each method were 
combined and elaborated to obtain a stronger understanding related to the research problem. This mixing method will

integrate a stronger understanding rather than only itself. (Creswell, 2018, p. 294)

In this study, the primary data source was the movie "I, Tonya." the secondary data sources were obtained from movie subtitles script, books, and journals.

The method of collecting data in this study used the documentation method supported with a corpus analysis based on the concordance technique. The first step, the movie was downloaded from the internet. The second step was watching and listening intensively to the character's conversation. Third, looking to the movie script that has been printed out to comprehend the utterances from the character's dialog. The last utterances, which contain the women's linguistic features, were sorted out based on women's linguistic features by highlighting in the movie script.

To get more accurate data, the corpus concordance technique was used to support the primary data. The first step, the movie subtitles script (Docx), was downloaded from the internet and converted into plain text (txt). Then, the movie script in AntConc corpus software was progressing to generate a concordance. After that, inserting words or phrases of types of women language features in the AntConc corpus software's column to find the specific data. The last step was identifying and elaborating the concordance data for further analysis.

The quantitative method was used to know the frequency of types of women's linguistic features of lexical hedges or filler, intensifier, and avoidance of strong swear words in the movie based on the concordance technique. The concordance result was elaborated with Creswell's (2018, p. 268) qualitative data analysis procedure. There were five steps of analyzing the data, 1) Organizing and preparing the data analysis, 2) Reading and looking at all the data, 3) Coding the data into categories, 4) Generate description and theme, and 5) Representing the description and theme.

\section{B. Lakoff's Theory of Women's Language}

Women's language became popular after Lakoff's research in 1975. It was described in her article entitled "Language and women places." She explained the fundamentals of women's language in the different aspects that make it different from men's language. Furthermore, to give one perspective to the reader, she also defines a clear understanding of women's language. She explained simply that women's language is a style used by women while they are speaking. Specifically, the characteristics of women's language tend to be weak, powerless, speak politely, and used standard form since they believe that the way they speak portrayed their social status in society.

The linguistics devices that deeply distinguish their language from men are; the first lexical hedges or filler. It is an utterance constructed with one or more words that expressed uncertainty from a lack of confidence such as well, you see, you know, I guess, I think, and umm. Tag question is midway between an outright statement and a yes-no question. It means the speaker does not want a yes-no question but expects a response from the addressee, for example "she is really smart, isn't she?". Rising intonation means the speaker raises their pitch of the voice while saying a statement. It usually occurs at the end of the statement. For example, "It is so nice." Empty adjectives usually sound excessive for men but more appropriate for women. Lakoff gave some examples of such as adorable, charming, and sweet. Precise color terms are several color terms rarely used by men but are often used by women. Lakoff in his research showed several colors such as mauve, beige, aquamarine, lavender, and magenta as the precise color terms. Intensifiers are affirming words such as, so, just really, very, and quite which are used by women. More precisely, the intensifier emphasizes a word that the object being aimed at has more meaning. Hypercorrect grammar is standard verb forms. It can be observed from the use of $g$ in verbs. (Lakoff cited in Holmes, 1992, p.314)

Super polite forms are women's speech features that make them sound more polite than men's (Lakoff; 1975: 56). Some words that represent politeness are "please", "thank you". In avoidance of strong swear words, women rarely vent their anger with swear words, they prefer a gentler way of serving their emotion due to reputation for a woman in society is more important. Lakoff (1975:50) gave examples of this type such as "fuck", 'bullshit', and "goddamn". They are not expected to uttering these words. The last, Emphatic stress is usually used to express something deeply in response to something that is happening. Women usually use empathy stress to emphasize and strengthen intent on their feelings. e.g., "it was a BRILLIANT performance."

\section{Result ANd Discussion}

Types of Women's Linguistic Features in the Craig's Gillespie Movie "I, Tonya"

\subsection{Lexical Hedges or Filler}

Lakoff defined lexical hedges or filler as an utterance constructed with one or more words that expressed uncertainty and a lack of confidence. Besides, the filler is also defined as a pause in the form of a phrase found in conversation to fill in a pause of breath, information that is not completely accurate, and as "meaningless particles." In this study, ten examples of lexical hedges and fillers were found in the "I' Tonya" movie. One of the following examples were presented below:

\author{
(Data 1) \\ (00:51:09 - 00:51:36) \\ Diane : You okay? \\ Tonya: Well... My skating career's over. I have no \\ savings. I ended up a waitress like my mom. \\ On the plus side, I'm unskilled.
}


The first data of the conversation above was done by two female characters named Tonya and Diane, who discussed Olympic skating champions. Tonya used the word "well," which was an indication of lexical hedge or filler. In the beginning, Diane came and approached Tonya, who was taking a break from her part-time work. She asked about Tonya's situation after retiring from skating. However, Tonya did not answer contextually to the question. She answered starting with the word "well.." Then, there were moments before she continued answering and telling her about the actual situation. From this interlude, it could be seen that Tonya had doubts about the actual state of her economy. Thus, the word well in the above conversation could be categorized as hedges because it reflected Tonya's expression of hesitation and lack of confidence.

Nowadays. The complexity of findings of women's language, especially lexical hedges or filler, where published claims sometimes contradict one another. Lakoff showed that lexical hedges could be categorized to women's linguistic features since women used it frequently than men. The data below shows the quantification of women and men characters using lexical hedges or filler in the "I' Tonya" movie.

Table 1. Lexical hedges or filler are used by the male and female characters in "I' Tonya" Movie.

\begin{tabular}{|l|c|c|c|}
\hline $\begin{array}{c}\text { Lexical Hedges } \\
\text { or Filler }\end{array}$ & Female & Male & Total \\
\hline Well & $20(8 \%)$ & $14(6 \%)$ & 34 \\
\hline Like & $\begin{array}{c}37 \\
(15 \%)\end{array}$ & $15(6 \%)$ & 52 \\
\hline You know & $20(8 \%)$ & $8(3 \%)$ & 28 \\
\hline I guess & $2(1 \%)$ & 1 & 3 \\
\hline I Think & $3(1 \%)$ & $3(1 \%)$ & 6 \\
\hline Hmmm & $2(1 \%)$ & $1(1 \%)$ & 3 \\
\hline Umm & $10(4 \%)$ & $12(5 \%)$ & 22 \\
\hline Uhh & $7(3 \%)$ & $19(8 \%)$ & 26 \\
\hline I mean & 34 & $8(3 \%)$ & 42 \\
\hline Yeah & $(14 \%)$ & & \\
\hline Total & $23(9 \%)$ & $9(4 \%)$ & 32 \\
\hline & 158 & 90 & 248 \\
\hline
\end{tabular}

Table 1 shows the quantification of lexical hedges uttered by the female and male characters in the " $I$ ' Tonya" movie. This data is a corpus data of 10677 words sample from a corpus of transcribed conversations from " $I$ ' Tonya" movie subtitles script. There were 158 lexical hedges used by women and only 90 expressions by men. The most frequently occurring hedges in the corpus with "like" accounting for almost 37 of the hedging devices and "I mean" 34 in the corpus. The male character also used lexical hedges frequently in "uh" about 19 devices. Overall, women used lexical hedges or filler frequently than men used. The data shown proved that the female character used more hedges than men in the "I' Tonya" movie.

\subsection{Tag question}

In the movie I 'Tonya, after being observed carefully and thoroughly, there is only one form of expression that contains the type of tag questions of women's linguistics features. The analysis of the data is explained below:

(Data 2)

(01:25:00 - 01:25:35)

Tonya: There's... There's more than what you're saying the story is, isn't there..? Did you do it?

Jeff : Shut up I'm telling you!!

From the conversation data, a phrase was classified as a type of women's linguistic feature of tag questions. It was "isn't there?". It was said by a female character named Tonya when talking to her husband, Jeff. They were talking about the truth of the accident from Nancy Kerrigan's leg breaking. At first, Jeff had told an incident about what he thought was true.

Nevertheless, Tonya still had doubts about the truth of the story. It is implied in the sentence, "There's more than what you're saying the story is, isn't there ..? ". The ending of the sentence ends in the form of tag questions. It clearly shows that she had other prejudices from the story. Then, the phrase "isn't there" can be classified as tag questions since she did not only want yes or no but expected a specific explanation. In this case, she expected the honesty of Jeff's alibi.

\subsection{Rising intonation on Declarative}

Rising intonation means the speaker raises their pitch of the voice while saying a statement. The utterance, which consists of intonation on declarative in "I' Tonya" movie, was performed below.

(Data 3)

(01:05:04 - 01:05:19)

You're not a secret agent. You're not a hitman. Just stay away from me!

The data above was a dialogue between female and male characters in the "I 'Tonya" movie. There was a male character named Shawn who was approaching Tonya during practice skating. He talked about a plan. However, Tonya was confused about what Shawn was discussing. She did not care about what Shawn's plan was. She stated that she did not want this plan to happen. Tonya refused Shawn's approval. Then, she said that Shawn was not a secret agent and was telling more specific information related to Shawn's life.

The above data reflects the rising tone uttered by Tonya from the sentence "Stay away from me.! ". Here, she raises her intonation when saying that statement. She brightly 
refused Shawn's plan and asked him to stay away from herself. It makes Shawn seriously take Tonya's statements. In this condition, by raising her intonation, she hoped that Shawn would not do the plan.

\subsection{Empty Adjective}

The speaker used empty adjectives to show their emotion of approbation or admiration of something. They convey their emotional reaction through empty adjectives rather than give specific information. In the " $I$ ' Tonya" movie, there was found several data that were considered as an empty adjective.

\section{(Data 4)}

(00:25:53 - 00:26:05)

Tonya : Think it needs more tulle? I want it to look pretty. Tulle's classy right?

Jeff : You think any more bout getting your high school G.E.D.?

From the data above, there was a word that can be classified as an empty adjective. That word was uttered by Tonya when talking about her dress's design with her husband. In the context of the conversation, Tonya was designing a dress for her skating champion. Then, she stood up, showing the result to her husband, and asked for advice on the dress. Tonya said that "I want it to look pretty." There was the word "pretty," which was included in the empty adjective from the expression. She said that it needed tulle in her dress because she wanted it to look pretty. Therefore, it implied Tonya's admiration of the dress through the word pretty.

\subsection{Intensifier}

Intensifiers are affirming words such as, so, just really, very, and quite which are used by women. Intensifier has almost the same function as hedging. However, words classified as intensifiers are more used to influence the interlocutor to take their statements more seriously and emphasize the intended meaning. The female character in this movie used some intensifiers. Those found four intensifiers; so, just, really, very. Some parts of the conversation which contained intensifiers were performed below.

(Data 5)

(00:55:34 - 00:55:41)

Lavona : So, what do you want from me? Money?

Tonya : God. I just wanted to see you.

In the above conversation, there is an intensifier in the word "just." The word was spoken by a female character named Tonya. In the beginning, Tonya visited her mother in a restaurant. She came to ask about the condition of her mother. However, her mother had a negative prejudice, which could be seen from her utterance. Her mother thought that Tonya was visiting her for a specific purpose, such as for money. However, Tonya emphasized that she met her mother not to get money but to see her mother's condition. It can be seen from the word "just" from the statement "God, I just wanted to see you". Tonya emphasized the purpose of her visit by saying that she had come to see his mother, who had not been seen for a long time. From this explanation, it can be said that it is clear that the word just in the above conversation can be classified into the intensifier women linguistics feature.

Tabel 2. An intensifier used by a female and male character in " $I$ ' Tonya" Movie

\begin{tabular}{|l|l|l|l|}
\hline Intensifier & Female & Male & Total \\
\hline Just & $58(41 \%)$ & $16(11 \%)$ & 74 \\
\hline So & $30(21 \%)$ & $16(11 \%)$ & 46 \\
\hline Very & $5(4 \%)$ & $1(1 \%)$ & 6 \\
\hline Really & $10(7 \%)$ & $4(3 \%)$ & 14 \\
\hline Total & $103(74 \%)$ & $37(26 \%)$ & 140 \\
\hline
\end{tabular}

Table 2 depicts the frequency of intensifier used between the female and male characters in the "I' Tonya" movie. There are five categories found that can be classified as an intensifier. They are "just, so, very, and really." The frequency of female and male intensifiers was significantly different. There are 103 statements containing intensifier uttered by the female character data, whereas male characters speak 37 utterances. It can be seen that the most type of intensifier used by the female character was "just," which was uttered 58 times between the others three categories of intensifier. Meanwhile, the male character used "just" and "so" as the most intensifier. All things considered that women used intensifiers more frequently than men.

\subsection{Hypercorrect' grammar}

A regular grammar used by the speaker when speaking is known as hypercorrect grammar. It aims to be respectful while also creating a space between the addressees. This study found some data as hypercorrect grammar used by the female character in the "I' Tonya" movie. The analysis is presented below:

\section{(Data 6)}

(00:51:29 - 00:51:36)

The Olympic Committee announced today that the next Olympics are going to be in two years instead of four.

The data above could be classified into the hypercorrect grammar of women's linguistic features. It was uttered by a female character named Diane. She stated this statement when visiting Tonya, who took a break from her part-time job at a restaurant. Diane said, ".. the next Olympics are going to be in two years instead of four." The statement has a standard verb form according to Lakoff's theory. This sentence is the grammar form of the Simple Future Tense. It 
consists of $\mathrm{S}+$ To Be (is, am, are) + Going To + Verb $1+\mathrm{O}$. The function of this grammar is to notify an upcoming event. Apart from that, this grammar form also serves as a more polite expression when speaking. From that sentence, Diane wanted to share some information that will be happening soon.

\subsection{Superpolite forms}

Super polite is showing a suitable manner towards others, as in behavior, speech, etc., The main character in this movie used "thank you, please and I am sorry" as the super polite forms. The analysis was shown below.

(Data 7)

$(01: 33: 37-01: 33: 40)$

Could you please just leave me alone? For now.

The word please in the example is a word that is included in the super polite form. Tonya uttered the word to the reporters who were waiting outside her house. The mass media surround Tonya, and she felt uncomfortable and disturbed. Therefore, she asked them to leave her alone. Tonya asked the reporter to leave her alone by saying the word "please" politely. She used that word so that reporters would not be offended by her intentions.

\subsection{Avoidance of strong swear word}

The swear word is offensive, used primarily as an expression of anger. Women rarely vent their anger with swear words, and they prefer a gentler way of serving their emotions due to reputation for a woman in society is more important. In this study, four data contain avoidance of strong swears words in the "I' Tonya" movie. The data were presented below.

\section{(Data 8)}

(00:28:57 - 00:29:23)

Tonya: I dressed pretty! God, you don't like the way I dress or talk or any of my music. It's like you want me to be an entirely different person!

There is a word "God" in the above conversation, which can be classified as avoidance of strong swear words. Tonya got unsatisfactory results when the results of the skating champion were announced. Her trainer advised that she should dress adequately according to the rules of the champion. However, Tonya confirmed that she was dressed well. She was not angry when given a suggestion. It can be seen from the word "God,...". The word "god" is a more subtle expression to show strong emotions.

Tabel 3. Avoidance of strong swear word used by the female and male character in "I' Tonya" movie

\begin{tabular}{|l|l|l|l|}
\hline Type & Female & Male & Total \\
\hline Honey & $6(33 \%)$ & $4(22 \%)$ & 10 \\
\hline
\end{tabular}

\begin{tabular}{|l|l|l|l|}
\hline God & $5(28 \%)$ & $2(11 \%)$ & 7 \\
\hline Sweetie & 0 & $1(5 \%)$ & 1 \\
\hline Total & $11(61 \%)$ & $7(39 \%)$ & 18 \\
\hline
\end{tabular}

The result is shown in table 3 of the frequency of the avoidance of strong swear words used by male and female characters in the "I' Tonya" movie. There are three expressions of avoidance of strong swear words expressed by the characters. They are Honey, God, and Sweetie. Female and male characters uttered 18 expressions of avoidance of strong swear words. Women used avoidance strong swear words $61 \%$ than men only $39 \%$. The most popular type used by female characters was honey accounting for 33\%. Meanwhile, men frequently used honey, accounting for $22 \%$. Overall, women used more avoidance strong swear words than men in the "I' Tonya" movie.

Lakoff mentioned that women are not expected to use expletive words. They tend to avoid using swear words because they will consider as unladylike. (2004, p.80). It is opposed to 'dear' or 'goodness' that is a more appropriate saying by women. However, several words are classified as swear words found in the "I' Tonya" movie. The data consist of swear words uttered by female character was shown in the data below:

Tabel 4. Swear words used by a female and male character in "I' Tonya" movie

\begin{tabular}{|l|l|l|l|}
\hline Type & Female & Male & Total \\
\hline Fuck & $35(38 \%)$ & $14(15 \%)$ & 49 \\
\hline Shit & $21(23 \%)$ & $8(8,8 \%)$ & 29 \\
\hline Goddamn & $3(3,2 \%)$ & $1(1 \%)$ & 4 \\
\hline Bullshit & $4(4,3 \%)$ & $1(1 \%)$ & 5 \\
\hline Damn & $1(1 \%)$ & $1(1 \%)$ & 2 \\
\hline Hell & $1(1 \%)$ & $1(1 \%)$ & 2 \\
\hline Total & $65(71,4 \%)$ & $26(28 \%)$ & 91 \\
\hline
\end{tabular}

Table 4 illustrated how female and male characters used swear words in the " $I$ ' Tonya" movie. It allows comparisons between the number of female characters who used swear words versus male characters who used swear words. Overall, it can be seen that women who used swear words were far higher than men. The prominence of a swear word is striking the female character expresses $71,4 \%$ compared to only $28 \%$ swear word used by the male character in "I' Tonya" movie. The most significant type of swear word uttered by female characters was "fuck" with almost $38 \%$. It can be seen that women used more swear words than men in the "I' Tonya" movie.

\subsection{Emphatic Stress}

Women usually use empathy stress to emphasize and strengthen intent on their feelings. In ' $I$ ' Tonya" movie, there are some phrases that could be categorized as emphatic stress, as presented below: 
(Data 9)

(00:09:05 - 00:09:07)

GOOD, Tonnie.! But check out sooner.

The sentence above is data that constitutes emphatic stress. It was "GOOD" uttered by the female character, Diane. In the context of the situation, Diane was standing outside the skating area. She was observing Tonya's movement intensively. Then she said emphatically, "Good" while she saw Tonya doing a great movement. It reflected Diane's praise of Tonya's movement, at the same time her admiration. According to Lakoff (1975: 56), emphatic stress is mainly to positive politeness to the addressee. In this case, Diane prefers to use emphatic stress to emphasize her utterance for Tonya.

\section{Conclusion}

In the last decade, many researchers are criticizing Lakoff's theory of women's language. Therefore, this study discussed whether a woman's language is still relevant nowadays. The findings from qualitative and quantitative data showed nine types of women linguistics features used by the female characters in the " $I$ ' Tonya" movie. Meanwhile, a type of women linguistics feature of the precise color term was not found.

Furthermore, three women linguistics (lexical hedges or filler, intensifier, and avoidance of strong swear word) used quantitative methods based on AntConc Corpus analysis. The data are taken from 10677 words of corpus data from "I' Tonya" movie subtitles script. The findings show that women used lexical hedges, accounting for $64 \%$ meanwhile men only $36 \%$. It is also found in intensifiers where women used accounting for 103 expressions and men only 37 expressions. However, in avoidance of strong swear words, women were using swear to account for $71 \%$.

In addition, the types of women linguistics features have their function on conversation employment. Five functions of women linguistics used by the female character in ' $I$ ' Tonya" movie are, firstly, to shows uncertainty. The female character shows uncertainty through two types; lexical hedges or filler and tag question. Second, to intensify and emphasize the utterance. Intensifier and emphatic stress are often uttered to emphasize an utterance. Thirdly, to get a response through rising intonation on declarative. Fourth, to express feelings through emphatic stress and empty adjectives, and the last one, to soften utterance by using superpolite form expression and avoidance of strong swear words.

\section{REFERENCES}

[1] Andriani, K., Ngurah Parthama, I. G. and Lirishati Soethama, P. (2018) 'Women's Language Features in Summer McKeen's Vlogs', Humanis, p. 735. DOI: 10.24843/JH.2018.v22.i03.p25.
[2] Asih Yuliananingrum, Suparno and Sujoko (2015) 'The Analysis on Male and Female Talk in Oprah Winfrey Show (Sociolinguistic Approach).', English Education. DOI: 4. 37. 10.20961/eed.v4i1.34714.

[3] Cameron, D. (2005) 'Language, Gender, and Sexuality: Current Issues and New Directions', Applied Linguistics, 26(4), pp. 482-502. DOI: 10.1093/applin/ami027.

[4] Carli, L. L. (1990) 'Gender, language, and influence.', Journal of Personality and Social Psychology, 59(5), pp. 941-951. DOI: 10.1037/0022-3514.59.5.941.

[5] Coates, J. (2015) Women, men, and language: A sociolinguistic account of gender differences in language. Routledge.

[6] Crawford, M. (1995) Talking difference: on gender and language. London; Thousand Oaks, Calif.: SAGE. Available at: http://site.ebrary.com/id/10567083 (Accessed: 7 January 2021).

[7] Creswell, J. W., and Creswell, J. D. (2018) Research design: qualitative, quantitative, and mixed methods approach. Fifth edition. Los Angeles: SAGE.

[8] Eckert, P. and McConnell-Ginet, S. (2013) Language and gender. Cambridge: Cambridge University Press. Available at: https://doi.org/10.1017/CBO9781139245883 (Accessed: 8 November 2020).

[9] Edwards, J. (2009) Language and identity: an introduction. Cambridge, UK; New York: Cambridge University Press (Key topics in sociolinguistics).

[10]Hall, K., and Bucholtz, M. (1995) Gender articulated: language and the socially constructed self. New York: Routledge. Available at: http://gateway.library.qut.edu.au/login?url=https://ww w.taylorfrancis.com/books/9781136045424 (Accessed: 19 January 2021).

[11] Holmes, J. (2008) An introduction to sociolinguistics. 3rd ed. Harlow, England ; New York: Pearson Longman (Learning about language).

[12] Kurniaty, N. (2018) 'Women's Language in the Movie Script of The Perks of being a Wallflower', Humanis, 22(2), pp. 542-548. DOI: 10.24843/JH.2018.v22.i02.p37.

[13] Lakoff (2004) Language and woman's place: Text and commentaries. Oxford University Press, USA.

[14] Sanjaya, I. B. G. D. (2018) 'Women's Language in “The Nanny Diaries” Movie', Humanis, 22(3), pp. 804-809. DOI: 10.24843/JH.2018.v22.i03.p35.

[15] Satria Wirasa, K., Winaya, I. M. and Alit Ida Setianingsih, N. K. (2018) 'Women's Language Used in the Video of Counter-Strike: Global Offensive Female Player', Humanis, p. $1039 . \quad$ DOI: 10.24843/JH.2018.v22.i04.p28.

[16] Soffie Jakobsson (2010) 'A Study of Female Language Feature in Same-Sex Conversation', Hogskolan I Gavle. 
[17] Svendsen, A. D. (2019) 'Lakoff and Women's Language', Leviathan: Interdisciplinary Journal in English, (4), pp. 1-11. DOI: 10.7146/lev.v0i4.112651.

[18] Wardhaugh, R. (2006) An introduction to sociolinguistics. 5th ed. Malden, Mass., USA: Blackwell Pub (Blackwell textbooks in linguistics, 4). 